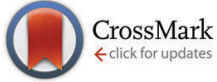

Cite this: Phys. Chem. Chem. Phys., 2017, 19, 9045

Received 21st January 2017 Accepted 28th February 2017

DOI: $10.1039 / c 7 c p 00476 a$

rsc.li/pccp

\section{The oxidation kinetics of thin nickel films between 250 and $500{ }^{\circ} \mathrm{C}$}

\author{
Y. Unutulmazsoy, R. Merkle, ${ }^{\star}$ D. Fischer, J. Mannhart and J. Maier
}

The oxidation kinetics of thin polycrystalline $\mathrm{Ni}$ films is of fundamental interest as well as being relevant for potential applications. It was investigated between 250 and $500{ }^{\circ} \mathrm{C}$ for $10-150 \mathrm{~nm}$ thick films. Even for the thinnest films, oxidation was found to be diffusion controlled. The high density of grain boundaries in the formed $\mathrm{NiO}$ layer leads to a tracer diffusion coefficient $\left(D_{\mathrm{Ni}}^{*}\right)$ that is higher than reported in the literature, indicating accelerated $\mathrm{Ni}$ diffusion along the grain boundaries. $\mathrm{Cr}$ segregation to the bottom interface in doped-NiO films hindered the acceleration of the oxidation of thin films.

\section{Introduction}

The growth of pore-free oxide layers on metals is determined by formation and migration of point defects and thus is an issue of basic importance. The oxidation kinetics of metals has been studied intensively for pure metals as well as for alloys. ${ }^{1-8}$ Great attention has been paid to decrease metal corrosion for engineering purposes in high-temperature applications. ${ }^{9}$ Studies were mostly performed on bulk samples or thick metal films at relatively high temperatures $\left(>500{ }^{\circ} \mathrm{C}\right) \cdot{ }^{10-16}$ However, there are only limited studies on the oxidation kinetics of thin metal films. ${ }^{3,17,18}$ On insulating substrates, the oxidation of thin metal films can easily be monitored by measuring the conductivity of the remaining unoxidized metal. Ni exhibits one of the highest oxidation rate constants (parabolic rate constants) among the corrosion resistant metals. ${ }^{19} \mathrm{NiO}$ is also one of the model materials for defect chemistry of binary oxides. We have therefore investigated the oxidation of thin Ni films in detail. In the present work, the oxidation kinetics is systematically studied for 10-150 nm thick Ni films between 250 and $500{ }^{\circ} \mathrm{C}$ under a variety of experimental conditions, e.g., under UV light illumination and different oxygen partial pressures. This work focuses on understanding the processes that determine the oxide growth rate, e.g., surface reaction or chemical diffusion, and also on increasing reaction-rate constants for potential applications such as irreversible data storage devices. ${ }^{19}$ Such long-term data storage materials require not only fast oxidation at moderately elevated temperatures $\left(\sim 500{ }^{\circ} \mathrm{C}\right)$ but also high corrosion resistance at room temperature.

This manuscript is organized in the following way. First the defect chemical models of undoped and donor-doped NiO are described, and the oxidation theories are summarized.

Max Planck Institute for Solid State Research, 70569, Stuttgart, Germany. E-mail:r.merkle@fkf.mpg.de
Then the experimental results on the oxidation of $\mathrm{Ni}$ films are presented, and the importance of grain boundary diffusion is shown. Attempts to accelerate the oxidation rate constant by Cr-doping and the difficulties of this approach are discussed.

\subsection{Defect chemistry of NiO}

Undoped NiO. Nickel oxide $\left(\mathrm{Ni}_{1-\delta} \mathrm{O}\right)$ is a metal-deficient p-type semiconductor which is thermodynamically stable in a large temperature $(T)$ and oxygen partial pressure $\left(p \mathrm{O}_{2}\right)$ range. $^{20}$ Nickel vacancies and electron holes $\left(h^{\bullet}\right)$ are predominant defects, but the ionization degree of nickel vacancies (singly ionized: $\mathrm{V}_{\mathrm{Ni}}^{\prime}$ or doubly ionized: $\mathrm{V}_{\mathrm{Ni}}^{\prime \prime}$ using the Kröger-Vink notation $^{21}$ ) in the temperature and partial pressure range of interest is still unclear. ${ }^{20}$ While the simultaneous presence of $\mathrm{V}_{\mathrm{Ni}}^{\prime}$ and $\mathrm{V}_{\mathrm{Ni}}^{\prime \prime}$ is reported in the literature, $\mathrm{V}_{\mathrm{Ni}}^{\prime \prime}$ is predominant at high temperatures and low $p \mathrm{O}_{2}$, whereas $\mathrm{V}_{\mathrm{Ni}}^{\prime}$ is predominant at low temperatures and high $\mathrm{pO}_{2}{ }^{22}$ The main reason for this shift is trapping of holes at low temperatures (see eqn (2)). Since the formal charge of the Ni vacancies does not directly affect the results in the present work, for simplicity only the expressions for doubly ionized vacancies are given below. Ref. 23 discusses the case that singly ionized nickel vacancies are majority defects.

The reaction for the incorporation of oxygen from the gas phase into the lattice is

$$
\begin{gathered}
\frac{1}{2} \mathrm{O}_{2} \leftrightharpoons \mathrm{O}_{\mathrm{o}}^{\times}+\mathrm{V}_{\mathrm{Ni}}^{\prime \prime}+2 \mathrm{~h}^{\bullet} \\
\mathrm{V}_{\mathrm{Ni}}^{\prime \prime}+\mathrm{h}^{\bullet} \leftrightharpoons \mathrm{V}_{\mathrm{Ni}}^{\prime},
\end{gathered}
$$

where $\mathrm{O}_{\mathrm{o}}^{\times}$represents an oxygen ion on its regular lattice site. ${ }^{21}$ The corresponding mass action constant is

$$
K=\frac{\left[V_{\mathrm{Ni}}^{\prime \prime}\right]\left[\mathrm{h}^{\bullet}\right]^{2}}{\sqrt{p \mathrm{O}_{2} / p \mathrm{O}_{2}^{\mathrm{o}}}}=\exp \left(-\frac{\Delta H^{\mathrm{o}}}{k_{\mathrm{B}} T}+\frac{\Delta S^{\mathrm{o}}}{k_{\mathrm{B}}}\right)
$$


where $k_{\mathrm{B}}$ is the Boltzmann constant, and $\Delta H^{\circ}$ and $\Delta S^{\circ}$ are the standard reaction enthalpy and entropy, respectively. Square brackets represent the concentration (molar fraction; the number of defects per NiO formula unit) of the respective species and the $p \mathrm{O}_{2}$ in the denominator is normalized to the standard pressure $p \mathrm{O}_{2}^{\circ}=1$ bar. In the intrinsic case, the electroneutrality condition is

$$
2\left[\mathrm{~V}_{\mathrm{Ni}}^{\prime \prime}\right]=\left[\mathrm{h}^{\bullet}\right],
$$

and both defect concentrations depend on $T$ and $p \mathrm{O}_{2}\left(\propto p \mathrm{O}_{2}{ }^{1 / 2}\right)$.

Donor-doped NiO. Doping is an important tool to significantly change point defect concentrations of the oxide. When $\mathrm{Ni}$ is substituted by a trivalent cation such as $\mathrm{Cr}^{3+}, \mathrm{Al}^{3+}$, and $\mathrm{Fe}^{3+}$, the positive defect $\mathrm{D}_{\mathrm{Ni}}^{\cdot}$ (donor dopant) increases the nickel vacancy concentration by modifying the electroneutrality condition:

$$
2\left[\mathrm{~V}_{\mathrm{Ni}}^{\prime \prime}\right]=\left[\mathrm{h}^{\bullet}\right]+\left[\mathrm{D}_{\mathrm{Ni}}^{\bullet}\right]
$$

When $\left[\mathrm{D}_{\mathrm{Ni}}^{\bullet}\right]$ largely exceeds $\left[\mathrm{h}^{\bullet}\right]$, the mass action constant is

$$
K=\frac{\left[\mathrm{D}_{\mathrm{N} i}^{\bullet}\right]\left[h^{\bullet}\right]^{2}}{\sqrt{p \mathrm{O}_{2} / p \mathrm{O}_{2}^{\circ}}}=\exp \left(-\frac{\Delta H^{\circ}}{k_{\mathrm{B}} T}+\frac{\Delta S^{\circ}}{k_{\mathrm{B}}}\right) .
$$

According to the mass action constant, donor doping increases the nickel vacancy concentration and decreases the hole concentration. Since eqn (2) shifts to the left side with donor doping, $\mathrm{V}_{\mathrm{Ni}}^{\prime \prime}$ will be the major Ni-defect within a much greater temperature and $p \mathrm{O}_{2}$ range, e.g., see ref. 24.

The defect concentrations (here in terms of molar fractions) for undoped and donor-doped $\mathrm{NiO}$ were calculated by using mass action constants from the literature ${ }^{25}$ for a small dopant concentration of $10^{-4}$. The calculations show that the vacancy concentration $\left[\mathrm{V}_{\mathrm{Ni}}^{\prime \prime}\right]$ is around $2.5 \times 10^{-6}$ for undoped NiO, while it is $2.5 \times 10^{-4}$ for donor-doped $\mathrm{NiO}$ at $600{ }^{\circ} \mathrm{C}$ at $0.21 \mathrm{bar}$ $\mathrm{O}_{2} \cdot{ }^{23}$ The results of the calculations demonstrate that even a small amount of dopant influences the defect concentrations by several orders of magnitude, and the influence increases at low temperatures. This information indicates the possibility to enhance cation diffusion by increasing the Ni vacancy concentration, thereby enhancing the oxidation rate constant.

\subsection{Oxidation kinetics of metals}

For the growth of a crack-free, adhering oxide layer on a metal film, the metal has to diffuse outwards and/or oxygen inwards, comprising transport of ionic and electronic carriers. If the molar volumes of the growing oxide layer and the metal do not differ extremely, the growing oxide layer is expected to be compact. ${ }^{26,27}$ Depending on the actual conditions, the oxidation kinetics is described by different models (see e.g., ref. 3): (i) the Cabrera-Mott theory ${ }^{2}$ describes the formation of very thin oxide films at relatively low temperatures, at which the electric field resulting from tunneling of electrons from the metal to chemisorbed oxygen species at the oxide surface accelerates ionic transport across the film. The decrease of the electric field with increasing film thickness leads to a negligible growth rate once a "limiting thickness" of a few nanometers is reached. Since under the conditions used in the present work the oxidation kinetics does not follow the Cabrera-Mott theory, it is not

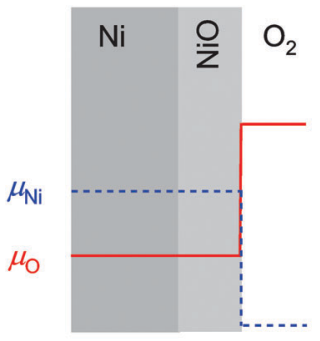

(a)

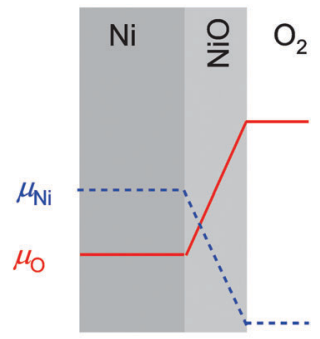

(b)
Fig. 1 The profiles of the chemical potentials $\left(\mu_{\mathrm{Ni}}\right.$ and $\left.\mu_{\mathrm{O}}\right)$ for (a) surface reaction controlled oxidation and (b) chemical-diffusion controlled oxidation (in practice the change of $\mu_{\mathrm{O}}$ and $\mu_{\mathrm{Ni}}$ within the oxide film is not perfectly linear).

discussed in detail. (ii) In the second case characterized by negligible field effects (relevant for thick films at high temperature), the kinetics is controlled either by chemical diffusion through the oxide layer as described by the Wagner theory or by surface reactions.

The Wagner theory considers the diffusion controlled formation of a compact oxide layer. ${ }^{1,27-29}$ The oxidation process is determined by the ambipolar conductivity $\left(\sigma^{\delta}=\sigma_{\text {eon }} \sigma_{\text {ion }} /\left(\sigma_{\text {eon }}+\sigma_{\text {ion }}\right)\right)$ together with the chemical potential gradient through the oxide film (see Fig. 1b). Depending on the defect chemistry and the electronic structure of the oxide, metal or oxygen ions can dominate ion diffusion, and the electronic current is carried by electrons or holes. For NiO, metal ions and holes are the major diffusing species. The flux of metal ions is directly related to the increase of the oxide thickness $X$ and is given by

$$
j_{\mathrm{Ni}}=-\frac{1}{4 F^{2}} \bar{\sigma}_{\mathrm{Ni}}^{\delta} \frac{\Delta \mu_{\mathrm{Ni}}}{X},
$$

where $F$ is the Faraday constant. The bar indicates the ambipolar conductivity averaged over the oxide film exposed to a step in a chemical potential $\Delta \mu_{\mathrm{Ni}}$. In $\mathrm{NiO}, \sigma_{\mathrm{Ni}}^{\delta}$ is approximately equal to the ionic conductivity because $t_{\text {eon }} \gg t_{\text {ion }}$, where $t_{\text {ion }}=\sigma_{\text {ion }} /$ $\left(\sigma_{\text {ion }}+\sigma_{\text {eon }}\right)=1-t_{\text {eon }}$ is the transference number of ions, and $t_{\text {eon }}$ is the transference number of electrons. According to eqn (7), the oxide growth rate becomes smaller with increasing film thickness as $\Delta \mu_{\mathrm{Ni}} / X$ decreases. Integration of the flux leads to the parabolic rate law

$$
X^{2}=k_{\mathrm{p}} t
$$

where $k_{\mathrm{p}}=\frac{1}{4 F^{2}} \bar{\sigma}_{\mathrm{Ni}}^{\delta} \Delta \mu_{\mathrm{Ni}}$. In general, the parabolic rate constant $k_{\mathrm{p}}$ is related to the tracer diffusion coefficient $D^{*}$ by

$$
k_{\mathrm{p}}=\bar{t}_{\mathrm{eon}} \bar{D}_{\mathrm{Ni}}^{*} \frac{\Delta \mu_{\mathrm{Ni}}}{k_{\mathrm{B}} N_{\mathrm{A}} T} .
$$

Here $D_{\mathrm{Ni}}^{*}$ is the diffusivity of $\mathrm{Ni}$ ions in NiO and $N_{\mathrm{A}}$ is the Avogadro number. Since $t_{\text {eon }}$ is close to 1 for NiO, eqn (9) results in

$$
k_{\mathrm{p}}=\frac{\bar{D}_{\mathrm{Ni}}^{*}}{k_{\mathrm{B}} N_{\mathrm{A}} T} \Delta \mu_{\mathrm{Ni}} .
$$

The chemical potential step across the oxide layer is

$$
\Delta \mu_{\mathrm{Ni}}=\Delta G_{\mathrm{ox}}=\Delta G_{\mathrm{ox}}^{\circ}+\frac{R T}{2} \ln \left(\frac{p \mathrm{O}_{2}}{p \mathrm{O}_{2}^{\circ}}\right),
$$


where $\Delta G_{\text {ox }}$ is the molar Gibbs energy of oxide formation and $\Delta G_{\mathrm{ox}}^{\circ}$ is the respective standard value, while $p \mathrm{O}_{2}^{\circ}$ is the standard pressure of 1 bar and $p \mathrm{O}_{2}$ is the actual oxygen partial pressure. For $\mathrm{Ni}$ vacancies, $D_{\mathrm{Ni}}^{*}$ is given by

$$
D_{\mathrm{Ni}}^{*}=\left[\mathrm{V}_{\mathrm{Ni}}^{\prime \prime}\right] D_{\mathrm{V}_{\mathrm{Ni}}^{\prime \prime}}
$$

where $D_{\mathrm{V}_{\mathrm{Ni}}^{\prime \prime}}$ is the diffusivity of $\mathrm{V}_{\mathrm{Ni}}^{\prime \prime}$, and $\left[\mathrm{V}_{\mathrm{Ni}}^{\prime \prime}\right]$ is the concentration in terms of site fraction. $D_{\mathrm{Ni}}^{*}$ is weakly dependent on $p \mathrm{O}_{2}$ because $\left[\mathrm{V}_{\mathrm{Ni}}^{\prime \prime}\right] \propto p \mathrm{O}_{2}{ }^{1 / 2}$ (see eqn (3)).

If the reaction is surface controlled, the oxygen and defect concentrations are homogeneous through the growing oxide film and there is a chemical potential step at the surface, corresponding to a deviation in oxygen concentration $\left(\delta c_{\mathrm{O}}\right)$ from the equilibrium value (Fig. 1a). The flux of ions is given by

$$
j_{\mathrm{O}}=-j_{\mathrm{Ni}}=-k^{\delta} \delta c_{\mathrm{O}}
$$

whereby $k^{\delta}=\left(\frac{c_{\mathrm{O}}}{R T} \frac{\delta \mu_{\mathrm{O}}}{\delta c_{\mathrm{O}}}\right) \cdot k^{*}$ is the effective surface reaction rate constant. $\delta c_{\mathrm{O}}$ remains constant as long as some metal remains beneath the oxide film. As a consequence, eqn (13) yields a constant flux of ions corresponding to a constant oxide thickness growth rate.

\section{Experimental methods}

Polycrystalline Ni films were prepared in a thickness range of 10-150 $\mathrm{nm}$ by e-beam evaporation at $\sim 10^{-6}$ Torr from $\mathrm{Ni}$ (99.5\%, Alfa Aesar) at room temperature on polycrystalline (KERAFOL, $0.25 \mathrm{~mm}$ thick) and single crystalline $\mathrm{Al}_{2} \mathrm{O}_{3}$ (sapphire, CrysTec, $0.25 \mathrm{~mm}$ thick) substrates. The thicknesses of the films were measured with a surface profilometer (Dektak XT, Bruker). Platinum electrodes $(\sim 400 \mathrm{~nm}$ ) were sputter-deposited (Edwards Auto 306 at $5 \times 10^{-2}$ mbar Ar, $60 \mathrm{~W}$ ) using a shadow mask.

The 0.1 and 1 at\% Cr-doped Ni alloys have been prepared by alloying the required amounts of $\mathrm{Cr}$ and Ni metals (for details see ref. 23). Chemical analysis by inductively coupled plasma optical emission spectroscopy (ICP-OES) yielded concentrations of $0.138 \pm 0.002 \% \mathrm{Cr}$ for nominally $0.1 \% \mathrm{Cr}$-doped $\mathrm{Ni}$, and $1.03 \pm 0.02 \%$ Cr for nominally $1 \%$ Cr-doped Ni. From these alloys thin films were grown by e-beam evaporation (under the same conditions as used for Ni films) and by scanning femto-pulsed laser deposition (femto-PLD). Using PLD, approximately $100 \mathrm{~nm}$ thick Cr-doped Ni films were deposited on sapphire substrates at a substrate temperature of $-180{ }^{\circ} \mathrm{C}$ for 2 hours using a femtosecond laser (442 fs, femtoRegenIC-375, High-Q-Laser $\mathrm{GmbH}, 516 \mathrm{~nm}$, 30-50 mW, $1 \mathrm{kHz}$ ). An alloyed target disc (1\% Cr-doped Ni, $\varnothing=10 \mathrm{~mm})$ was rotated $(1.4 \mathrm{rpm})$ at a fixed angle in a vacuum chamber $\left(3 \times 10^{-8} \mathrm{mbar}\right)$ and ablated by a horizontal line scan (galvanometer mirror box, HurryScan25, Scanlab AG, $50 \mathrm{~mm} \mathrm{~s}^{-1}$ ) of the laser beam focused on the target surface (spot size of $0.04 \mathrm{~mm}$, for further details on the method see ref. 30). The substrate temperature was controlled using a Pt-100 temperature sensor placed in the sample holder and fixed at $-180{ }^{\circ} \mathrm{C}$ during deposition.

DC magnetron sputtering (ATC 1500-F Sputtering System, Aja International Inc.) was used for the deposition of $100 \mathrm{~nm}$ thick 1\% Cr-doped Ni films. The films were grown by using simultaneous sputtering of $\mathrm{Ni}$ and $\mathrm{Cr}$ targets at $250 \mathrm{~W}$ and $3 \mathrm{~W}$, respectively. $^{23}$

During the oxidation of the films in air in a tube furnace, the resistance changes were measured laterally across the samples by two-point electrical impedance spectroscopy (Newton PSM1700 and Novocontrol Alpha-A High Performance Frequency Analyzer, $100 \mathrm{~Hz}$ to $1 \mathrm{MHz}$ at $100 \mathrm{mV} \mathrm{AC}$ amplitude) and fitted with an equivalent circuit modeling software (ZView, Scribner Associates, Inc.). The oxide thickness was calculated from the resistance values of the remaining metallic part of the film, considering the molar volume difference between the metal and the oxide.

Additional measurements under modified experimental conditions, such as UV light exposure, different oxygen partial pressures, and ozone atmosphere, were performed to further investigate the oxidation kinetics of Ni. More experimental details are given in ref. 23 .

X-ray photoelectron spectroscopy (XPS), AXIS ULTRA from Kratos Analytical Ltd, was used to determine Cr dopant concentration depth profiles of the metallic and oxide films by $\mathrm{Ar}$ ion sputtering $(4 \mathrm{kV})$. The peak positions were compared with the NIST XPS database. According to XPS, the native oxide layer on Ni films has a typical thickness below $3 \mathrm{~nm}$.

Scanning electron microscopy (SEM) was used to determine the grain size of the metal and the oxide films with a Zeiss Merlin microscope in secondary electron detection mode. Transmission electron microscopy (TEM), Philips CM 200, was applied to investigate the microstructure of the films. TEM samples were prepared by focused ion beam (FIB) while observing the process using a scanning electron microscope (Zeiss Crossbeam 1540 ESB).

\section{Results and discussion}

\subsection{Oxidation kinetics of nickel films}

Fig. 2a shows the increase of oxide layer thickness with time in a $\log -\log$ plot as an exemplary of in situ thin film oxidation measurements. The slope is close to $1 / 2$, indicating a parabolic rate law (diffusion controlled oxidation). If the reaction was surface controlled, the oxide film thickness would grow linearly in time (slope $=1$ ). For the film thicknesses between 10 and $150 \mathrm{~nm}$, the slope of $1 / 2$ indicated in Fig. $2 \mathrm{~b}$ confirms the diffusion controlled oxidation. Furthermore, the parabolic rate constant for films of different thicknesses and different substrates (polycrystalline $\mathrm{Al}_{2} \mathrm{O}_{3}$ or sapphire) yields essentially the same value (Fig. 3a).

$\mathrm{Ni}$ films were oxidized with different $p \mathrm{O}_{2}$, ozone atmosphere, and UV light exposure (Fig. 3b). These experiments confirmed that in a temperature range of $250-500{ }^{\circ} \mathrm{C}$, the oxidation kinetics of $\mathrm{Ni}$ is diffusion controlled for films of 10-150 nm thicknesses. This conclusion is drawn because the different experimental conditions, which are expected to strongly accelerate (UV, $\mathrm{O}_{3}$ ) or decelerate (low $\mathrm{pO}_{2}$ ) the surface reaction, did not significantly change the overall oxidation rate constant.

The fact that the oxidation of thin Ni films is diffusion controlled is attributed to the comparably small $D_{\mathrm{Ni}}^{*}$ values of NiO. 
(a)

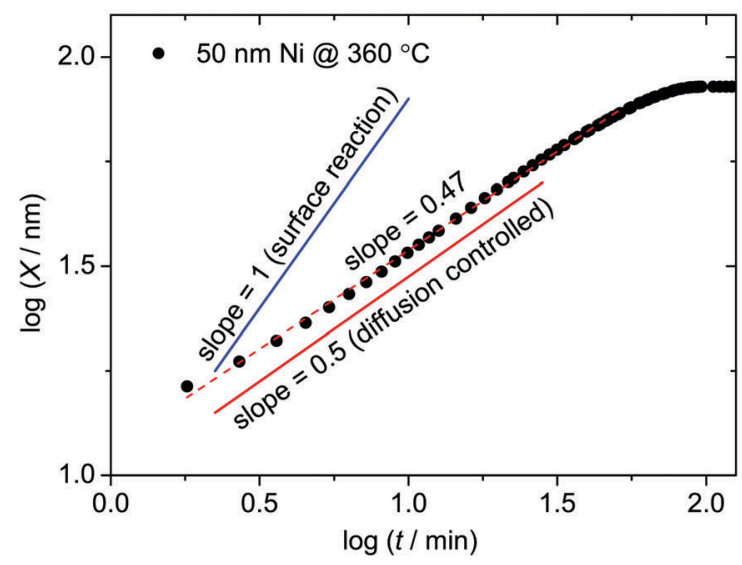

(b)

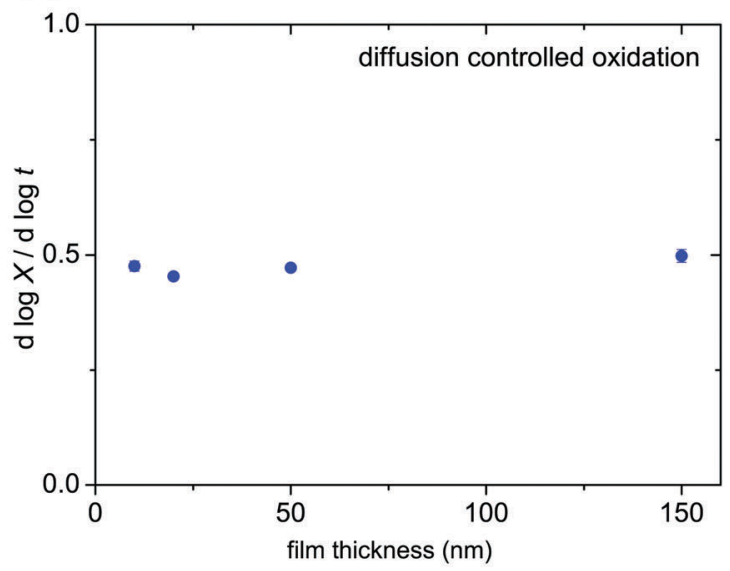

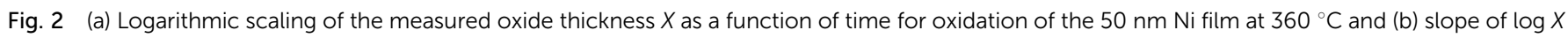
$v s$. $\log t$ as a function of the measured film thickness.
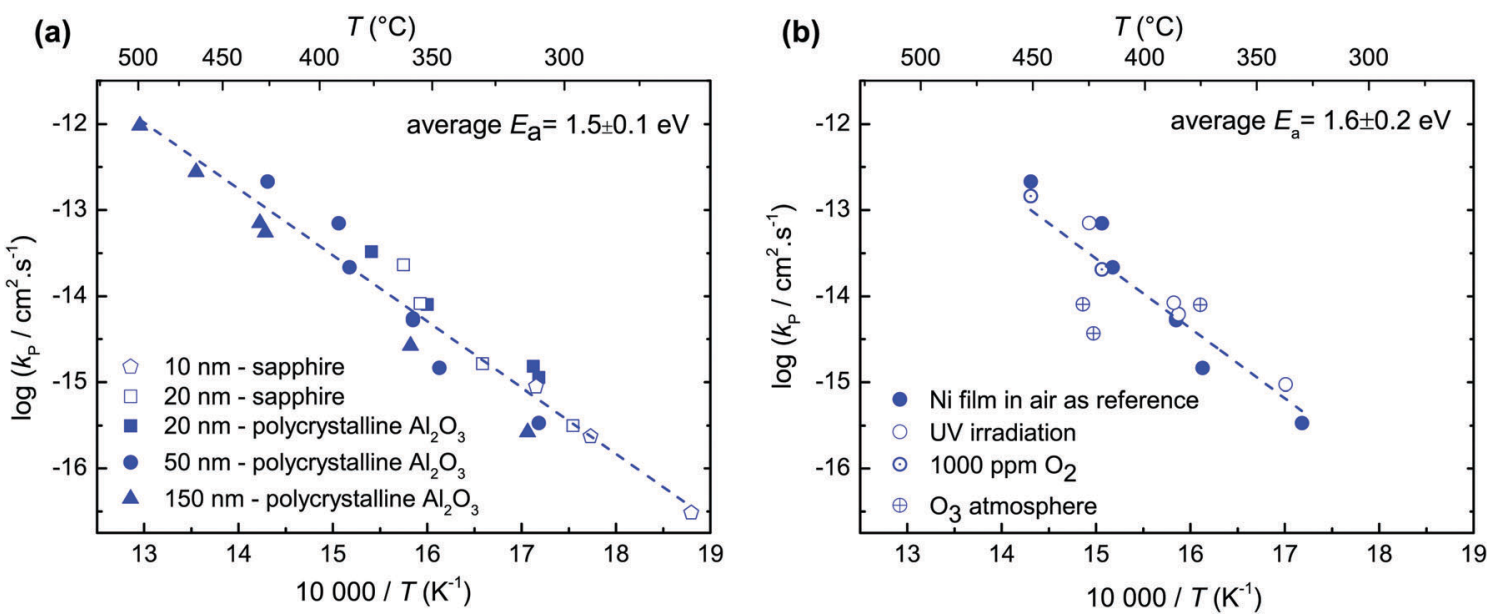

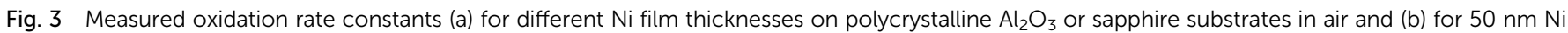
films on polycrystalline $\mathrm{Al}_{2} \mathrm{O}_{3}$ substrates under different experimental conditions.

In general, the rate determining process is expected to change from diffusion controlled to surface reaction controlled below a certain critical thickness which is given by $l_{\mathrm{c}} \approx D^{*} / k^{*}\left(k^{*}\right.$ : surface reaction rate, $l_{\mathrm{c}}$ : critical sample thickness, $D^{*}$ : tracer diffusion coefficient). ${ }^{31}$ The value of $l_{\mathrm{c}}$ ranges typically from 1 to $100 \mu \mathrm{m}$ for mixed conducting perovskites. ${ }^{31}$ Although the smallest sample thickness in the present work equaled only $10 \mathrm{~nm}$, a change from diffusion control to surface reaction control was not observed. Also upper limits of $k^{*}$ values were calculated in the present study for $10 \mathrm{~nm}$ NiO films using $D_{\mathrm{Ni}}^{*}$ values. These values are comparable to $k^{*}$ of redox-active mixed conducting perovskites, ${ }^{32}$ while the tracer diffusivity in $\mathrm{NiO}$ is much lower than the tracer diffusivity in perovskites. ${ }^{33,34}$ We therefore conclude that $l_{\mathrm{c}}$ in $\mathrm{NiO}$ is smaller by orders of magnitude than in perovskites.

The temperature range studied in the present work was 250 to $500{ }^{\circ} \mathrm{C}$, whereas the literature studies were mainly performed in a temperature range between 500 and $1400{ }^{\circ} \mathrm{C} .{ }^{10-16}$ Selected literature results ${ }^{11-13,35,36}$ and the results of this work are shown in Fig. 4 . The scatter of the literature $k_{\mathrm{p}}$ values reflects the influence of several factors on the oxidation of $\mathrm{Ni}$ : the nature and concentration of impurities, the grain size of the growing oxide, ${ }^{3}$ preparation techniques of the metal (annealed and cold worked), ${ }^{37}$ and crystal orientation. ${ }^{38}$ The oxidation of $\mathrm{Ni}$ films in the present work reveals faster oxidation compared to the reported data in the literature. ${ }^{11-13,35,36}$

The vast majority of polycrystalline samples have a higher oxidation rate constant than the $k_{\mathrm{p}}$ values calculated from single crystalline $D_{\mathrm{Ni}}^{*}$ values, and a lower activation energy as shown in Fig. 4. This result indicates that the grain boundaries provide fast diffusion paths as indicated in the literature. ${ }^{3,39}$ The activation energy in Atkinson and Taylor's work is given as $2.6 \mathrm{eV}$ for bulk diffusion, $2.0 \mathrm{eV}$ for dislocation diffusion and $1.8 \mathrm{eV}$ for grain boundary diffusion of $\mathrm{Ni}$ in NiO. ${ }^{39}$ Although the values of the activation energies differ in the literature, the present results $\left(E_{\mathrm{a}}\right.$ of $D_{\mathrm{Ni}}^{*}$ calculated from $k_{\mathrm{p}}$ of $\left.1.7 \pm 0.1 \mathrm{eV}\right)$ are in good agreement with the published values, especially with the results reported by Atkinson and Taylor. ${ }^{39}$ The $k_{\mathrm{p}}$ values of the present work are two orders of magnitude higher than for 


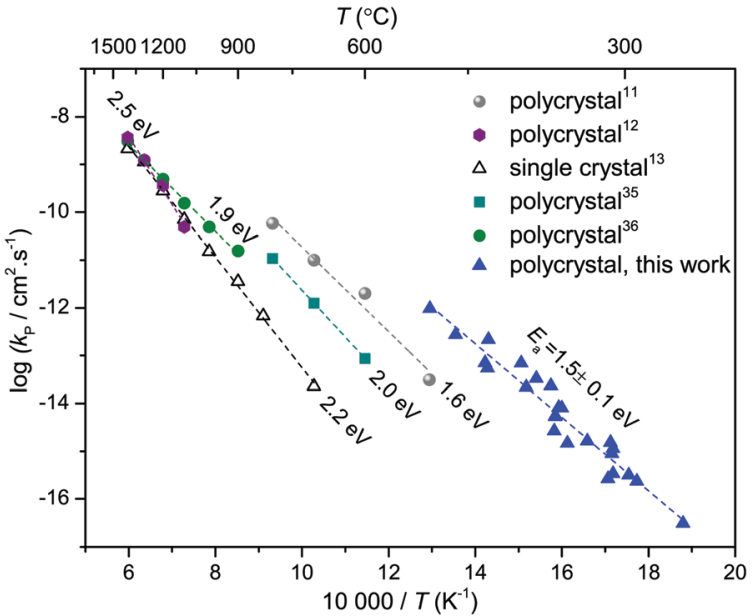

Fig. 4 Parabolic rate constants for Ni oxidation as reported in ref. 11-13, 35 and 36 compared to the results of this work. Open symbols were calculated from eqn (10) using $D_{\mathrm{Ni}}^{*}$ values of single crystalline $\mathrm{NiO}$ from ref. 13. Since the $\mathrm{pO}_{2}$ range of different data sets is small $\left(0.2\right.$ to 1 bar $\left.\mathrm{O}_{2}\right)$ and the $\mathrm{pO}_{2}$ dependence of $k_{\mathrm{p}}$ is weak, these data sets are comparable.

the large-grained polycrystalline samples reported in ref. 11, which is ascribed to the small grain sizes of the samples in the present work. The grain sizes of a partly oxidized $100 \mathrm{~nm}$ thick Ni film were investigated by SEM and TEM, as shown in Fig. 5 . The lateral grain size of the metallic layer is $\sim 100 \mathrm{~nm}$, whereas the grain sizes of the oxide layer vary between 10 and $30 \mathrm{~nm}$. The pore formation between $\mathrm{Ni}$ and $\mathrm{NiO}$ shown in Fig. 5 was attributed to faster grain boundary diffusion of $\mathrm{Ni}$ in $\mathrm{NiO}$ compared to $\mathrm{Ni}$ in $\mathrm{Ni}^{40}$

The effective diffusion coefficient can be modeled assuming a parallel switching of bulk transport and fast grain boundary diffusion according to

$$
D_{\mathrm{eff}}^{*}=g D_{\mathrm{gb}}^{*}+(1-g) D_{\mathrm{g}}^{*}
$$

where $D_{\text {eff }}^{*}$ is the effective diffusion coefficient, $D_{\mathrm{gb}}^{*}$ the grain boundary diffusion coefficient, and $D_{\mathrm{g}}^{*}$ the grain (bulk) diffusion coefficient. The thickness of the grain boundary $(\delta)$ is assumed to be $1 \mathrm{~nm}$ while the average grain size $(d)$ is $20 \mathrm{~nm}$ as measured by TEM for the samples in this work. The volume fraction of the grain boundaries $g$ is calculated to be equal to 0.1 according to

(a)

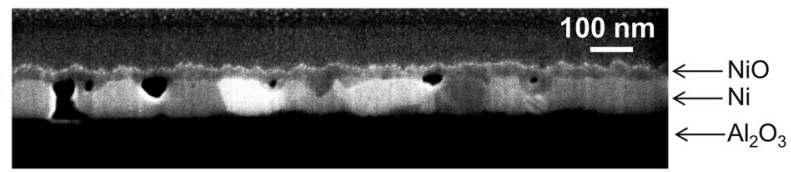

(b)

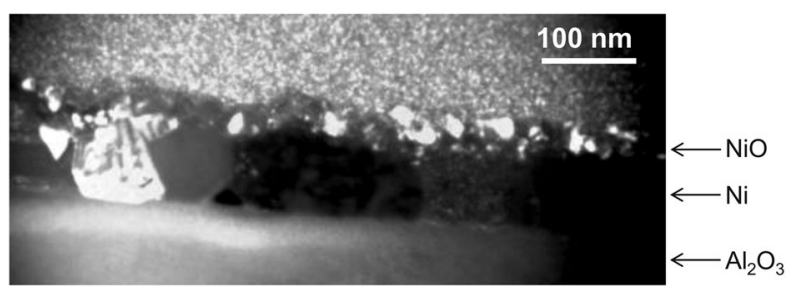

Fig. 5 Cross-sectional (a) SEM and (b) TEM images of the partly oxidized $100 \mathrm{~nm}$ Ni film. $g=q \delta / d$ and by using $q=2$ for the thin films (columnar grains; $q=1$ would correspond to the microstructure of vertical lamellae ${ }^{41}$ ).

Fig. 6 shows that in $\mathrm{NiO}$ the grain boundary diffusion coefficient below $700{ }^{\circ} \mathrm{C}$ exceeds the bulk diffusion coefficient by more than five orders of magnitude. Fig. 6 furthermore shows that $D_{\text {eff }}^{*}$ is close to $D_{\mathrm{gb}}^{*}$, revealing that grain boundaries control the diffusion of $\mathrm{Ni}$ in the present thin NiO films. Using the calculated $D_{\mathrm{gb}}^{*}$ for a ceramic sample which has a $0.16 \mu \mathrm{m}$ grain size yields $D_{\text {eff }}^{*}=9.4 \times 10^{-14} \mathrm{~cm}^{2} \mathrm{~s}^{-1}$ at $560{ }^{\circ} \mathrm{C}$, which is in reasonable agreement with a measured diffusion coefficient of $1.8 \times 10^{-14} \mathrm{~cm}^{2} \mathrm{~s}^{-1}$ at $560{ }^{\circ} \mathrm{C}$, as in ref. 11 . We therefore conclude that the accelerated grain boundary transport properties of the NiO thin films are quite similar to those of the oxide-ceramic samples.

\subsection{Oxidation kinetics of $\mathrm{Cr}$-doped $\mathrm{Ni}$ films}

E-beam evaporated films. Donor doping $\left(\mathrm{Al}^{+3}, \mathrm{Cr}^{+3}\right.$, etc. $)$ in $\mathrm{NiO}$ is expected to increase the nickel vacancy concentration and therefore to increase the parabolic rate constant. It was shown that Al doping increases the oxidation rate constant via an increased cation vacancy concentration above $1000{ }^{\circ} \mathrm{C}$, but decreases it below $1000{ }^{\circ} \mathrm{C}$, as caused by $\mathrm{Al}$ segregation to the grain boundaries. ${ }^{4,42}$ Although there is a similar result for the $\mathrm{Cr}-\mathrm{Ni}$ alloy below $1000{ }^{\circ} \mathrm{C},{ }^{43}$ it is also reported that $\mathrm{Cr}$ increases the reaction rate constant of $\mathrm{Ni}$ below $1000{ }^{\circ} \mathrm{C}$ if the $\mathrm{Cr}$ concentration does not exceed the solubility limit. ${ }^{44-46}$ The solubility limit of $\mathrm{Cr}$ in $\mathrm{NiO}$ is reported to be equal to $\sim 1-2 \%$ between 1000 and $1200{ }^{\circ} \mathrm{C}$, and to be smaller at lower temperatures. ${ }^{24,43,47,48}$ In the present work, $\mathrm{Cr}^{3+}$ was chosen as a donor dopant because of its lower size mismatch to $\mathrm{Ni}^{2+}$ compared to $\mathrm{Al}^{3+}$. The oxidation of Cr-doped Ni samples with low doping concentrations (0.1 and 1 at $\%$ ) was investigated with the intention to increase the reaction rate constant. However, as shown in Fig. 7, the Cr-doped $\mathrm{Ni}$ films did not show significant changes in the oxidation rate constant compared to the undoped Ni films.

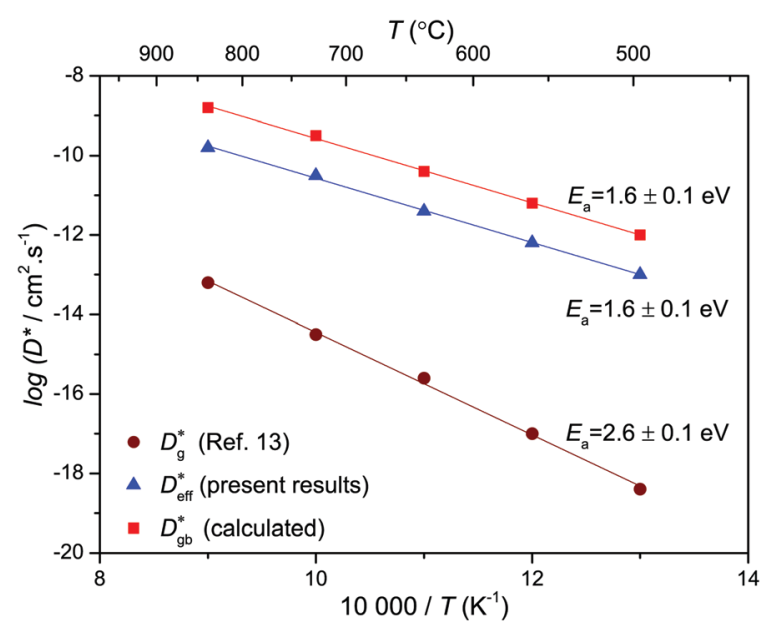

Fig. 6 Comparison of the calculated grain boundary diffusion coefficients ( $D_{\mathrm{gb}}^{*}$ : squares) derived using eqn (14), the effective diffusion coefficient derived using eqn (10) from measured $k_{\mathrm{p}}$ values in this work $\left(D_{\mathrm{eff}}^{*} \sim D_{\mathrm{Ni}}^{*}\right.$ : triangles), and the bulk diffusion coefficient ( $D_{\mathrm{g}}^{*}$ : circles) from ref. 13. 


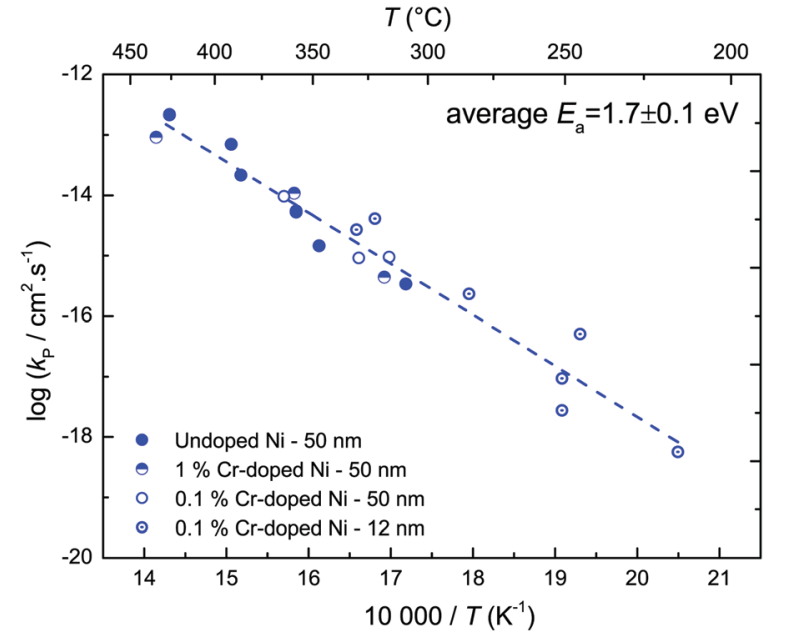

Fig. 7 Measured oxidation rate constants of Ni films: undoped $(50 \mathrm{~nm}$ on the polycrystalline substrate), $1 \% \mathrm{Cr}$-doped $\left(50 \mathrm{~nm}\right.$ on the polycrystalline $\mathrm{Al}_{2} \mathrm{O}_{3}$ substrate), and $0.1 \% \mathrm{Cr}$-doped (50 $\mathrm{nm}$ and $12 \mathrm{~nm}$ on the sapphire substrate).

To understand the reason for the Cr dopant inactivity, we performed XPS and TEM studies on the Cr-doped Ni films.

The measured concentration depth profiles of 0.1 and $1 \%$ Cr-doped Ni samples before and after oxidation analyzed by
XPS with Ar ion sputtering are given in Fig. 8. The XPS depth profiles revealed an enhanced amount of $\mathrm{Cr}$ on the metallic sample surface. $\mathrm{Cr}_{2} \mathrm{O}_{3}$ has a significantly more negative standard free energy of formation than $\mathrm{NiO}$, therefore $\mathrm{Cr}$ accumulates in the native oxide layer.

After oxidation of the films, most $\mathrm{Cr}$ is found as a segregated layer at the bottom of the film. Obviously, the outward diffusion of Cr through the growing oxide layer is slower than Ni diffusion, which is also observed in the literature. ${ }^{4-51}$ Since the $\mathrm{Cr}$ dopant is evidently strongly depleted in most of the growing oxide layer, it is understandable that the Cr-doped Ni films showed similar oxidation rate constants to undoped Ni films.

TEM studies illustrate the morphology of fully oxidized Cr-doped Ni films for 0.1 and $1 \%$ Cr. While the bottom layer is not easily visible in Fig. 9a for $0.1 \% \mathrm{Cr}$, the presence of a bottom layer corresponding to the Cr-enriched zone is clear for $1 \%$ Cr films (Fig. 9b).

Magnetron sputter-deposited films. The oxidation rate constants of $50 \mathrm{~nm}$ thick magnetron sputtered Cr-doped Ni films were found to be similar to those of films grown by e-beam evaporation. The XPS depth profile of the magnetron sputtered sample reveals that it is difficult to obtain homogeneous $\mathrm{Cr}$ distributions in thin $\mathrm{Ni}$ films grown by magnetron sputter-deposition as well as by e-beam evaporation.
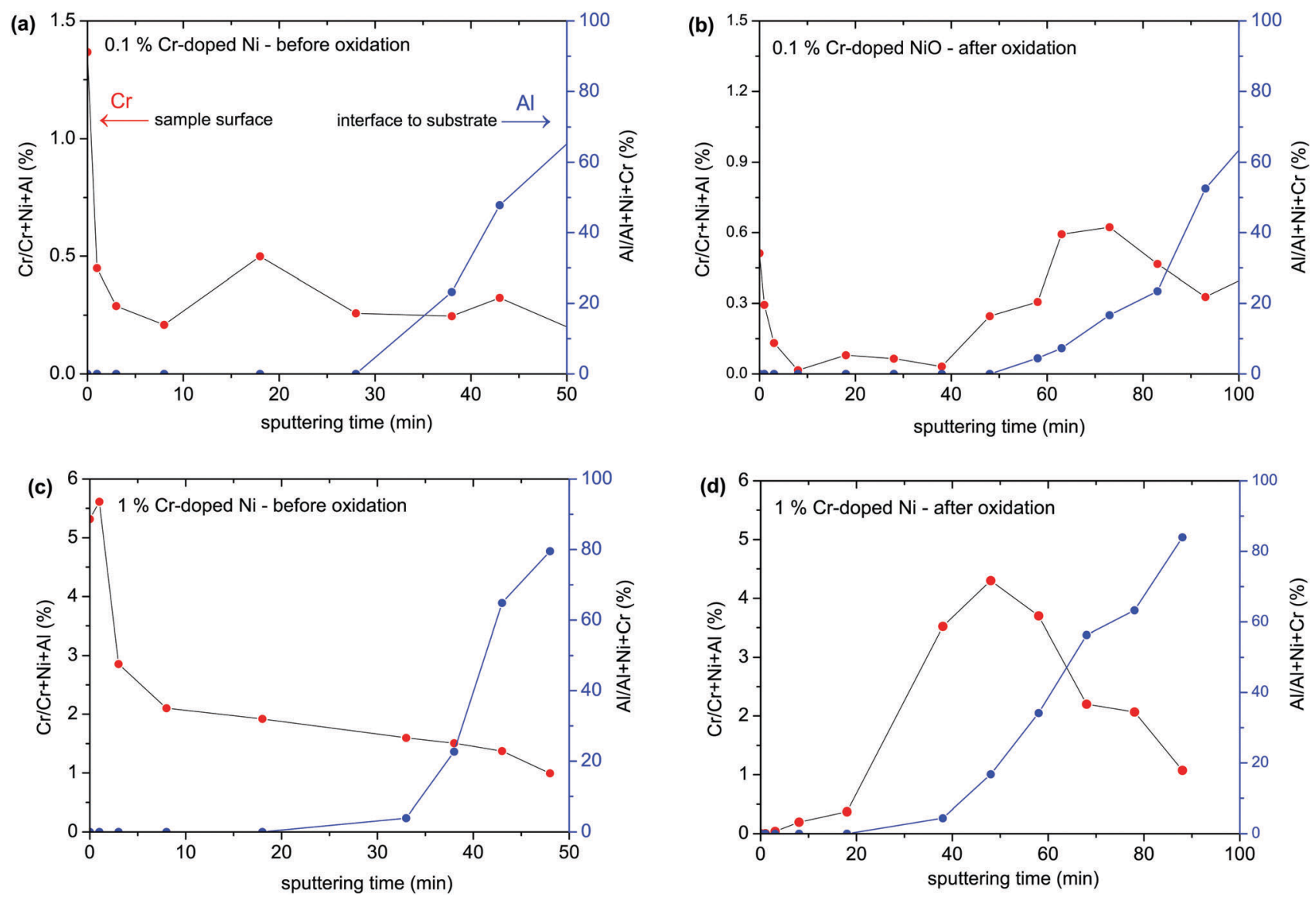

Fig. 8 Concentration depth profile analysis by XPS of (a) the $0.1 \% \mathrm{Cr}$-doped Ni metal film, (b) the $0.1 \% \mathrm{Cr}$-doped Ni oxidized film, (c) the $1 \% \mathrm{Cr}$-doped Ni metal film, and (d) the $1 \% \mathrm{Cr}$-doped $\mathrm{Ni}$ oxidized film. The raise of the $\mathrm{Al}$ signal at long sputtering times indicates the sputtering process reaching the $\mathrm{Al}_{2} \mathrm{O}_{3}$ substrate. 
(a)

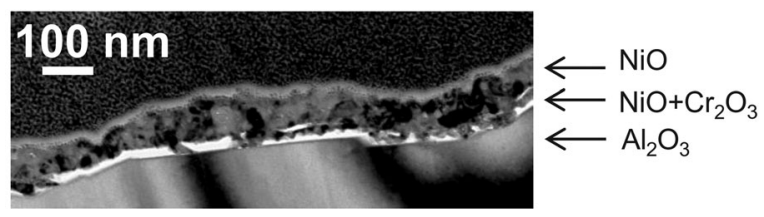

(b)

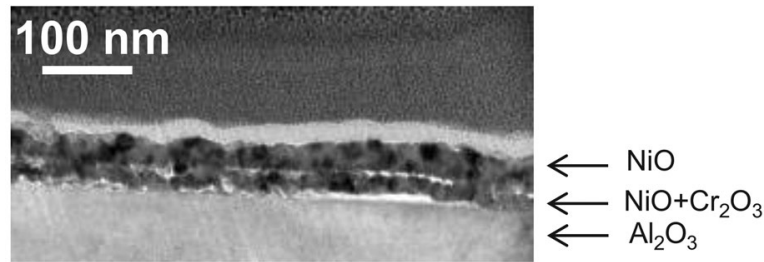

Fig. 9 Cross-sectional TEM images of (a) $0.1 \% \mathrm{Cr}$-doped $\mathrm{NiO}$ and (b) $1 \%$ $\mathrm{Cr}$-doped $\mathrm{NiO}$ films grown on the polycrystalline $\mathrm{Al}_{2} \mathrm{O}_{3}$ substrates.

Low-temperature PLD grown films. To obtain homogeneous $\mathrm{Cr}$ distribution in the metal films, Cr-doped $\mathrm{Ni}$ films were grown by femto-PLD at a substrate temperature of $-180{ }^{\circ} \mathrm{C}$. Although the XPS and EDX analysis of the metallic film implies that the Cr distribution is close to the desired dopant concentration through the film thickness $(1 \% \mathrm{Cr})$, the inhomogeneous sample thickness of these films prevented us from obtaining meaningful oxidation rate constant values.

\section{Conclusions}

The rate determining process for the oxidation of 10-150 nm thick Ni films at $250-500{ }^{\circ} \mathrm{C}$ is found to be diffusion of nickel via nickel vacancies through the oxide layer. The process is well described by the Wagner theory. The oxidation is diffusion controlled even for the thinnest films $(10 \mathrm{~nm})$ because the cation tracer diffusion coefficient in most common binary oxides is comparably low (in contrast to the oxygen tracer diffusion coefficient in perovskites). The increased oxidation rate constants and therefore the effective diffusion coefficients for the present samples with a much smaller oxide grain size compared to the literature show the importance of fast grain boundary diffusion. While donor doping is expected to increase the parabolic rate constant of $\mathrm{Ni}$ films, our measurements of e-beam evaporated and magnetron sputter deposited Cr-doped films show no change in the oxidation rate constant because of severe $\mathrm{Cr}$ segregation to the interface between the NiO film and the substrate.

\section{Acknowledgements}

The authors gratefully acknowledge the technical support and valuable discussions provided by Yvonne Stuhlhofer, Helga Hoier, Mitsuharu Konuma, Bernard Fenk, Fritz Phillipp, Marion Kelsch, Reinhart Völker, Gerhard Werner, Matej Fonovic, and Iman Rastegar.

\section{References}

1 C. Wagner, Z. Phys. Chem., Abt. B, 1933, 21, 25-41.

2 N. Cabrera and N. Mott, Rep. Prog. Phys., 1949, 12, 163-184.
3 A. Atkinson, Rev. Mod. Phys., 1985, 57, 437-470.

4 N. Halem, M. Abrudeanu and G. Petot-Ervas, J. Mater. Sci. Eng. B, 2011, 176, 1002-1009.

5 M. Tsuchiya, S. K. R. S. Sankaranarayanan and S. Ramanathan, Prog. Mater. Sci., 2009, 54, 981-1057.

6 W. W. Smeltzer and D. J. Young, Prog. Solid State Chem., 1975, 10, 17-54.

7 R. Haugsrud, J. Mater. Sci. Eng. A, 2001, 298, 216-226.

8 K. R. Lawless, Rep. Prog. Phys., 1974, 37, 231.

9 A. Galerie, High Temperature Corrosion of Chromia-forming Iron, Nickel and Cobalt-base Alloys in Shreir's Corrosion, Elsevier Ltd, Amsterdam, 2010.

10 A. Hughes, A. Atkinson and A. Chadwick, MRS Online Proc. Libr., 1984, 24, 27-37.

11 A. Atkinson, R. Taylor and A. Hughes, Philos. Mag. A, 1982, 45, 823-833.

12 S. Mrowec and Z. Grzesik, J. Phys. Chem. Solids, 2004, 65, 1651-1657.

13 A. Atkinson and R. I. Taylor, J. Mater. Sci., 1978, 13, 427-432. 14 S. Song and P. Xiao, J. Mater. Sci. Eng. A, 2002, 323, 27-31. 15 S. Mrowec, Z. Grzesik, B. Rajchel, A. Gil and J. Dabek, J. Phys. Chem. Solids, 2005, 66, 115-120.

16 S. Mrowec and K. Przybylski, Oxid. Met., 1985, 23, 107-139. 17 M. Graham and M. Cohen, J. Electrochem. Soc., 1972, 119, 879-882.

18 F. P. Fehlner, J. Electrochem. Soc., 1984, 131, 1645.

19 Y. Unutulmazsoy, R. Merkle, I. Rastegar, J. Maier and J. Mannhart, APL Mater., 2017, 5, 042302.

20 P. Kofstad, Nonstoichiometry, Diffusion, Electrical Conductivity in Binary Metal Oxides, Wiley-Interscience, New York, 1972.

21 F. Kröger and H. Vink, Solid State Phys., 1956, 3, 307-435. In this notation, the type of defect is represented by a major symbol (e.g., V: vacancy), the site is indicated by a subscript $\left(\right.$ e.g., $\mathrm{O}_{\mathrm{o}}$ or $\left.\mathrm{V}_{\mathrm{Ni}}\right)$ and the relative charge of defect is indicated by a superscript (negative charge: ${ }^{\prime}$ and positive charge: ${ }^{\bullet}$ ). $\mathrm{O}_{\mathrm{O}}^{\times}$represents an oxygen ion on its regular lattice site, $\mathrm{V}_{\mathrm{Ni}}^{\prime \prime}$ is a nickel vacancy on a nickel site which is doubly ionized.

22 R. Farhi and G. Petot-Ervas, J. Phys. Chem. Solids, 1978, 39, 1175-1179.

23 Y. Unutulmazsoy, PhD Thesis, University of Stuttgart, 2016.

24 H. Meier and R. Rapp, Z. Phys. Chem., 1971, 54, 168-189.

25 G. Koel and P. Gellings, Oxid. Met., 1972, 5, 185-203.

26 R. E. Bedworth and N. B. Pilling, J. Inst. Met., 1923, 29, 529-582.

27 H. Schmalzried, Chemical Kinetics of Solids, John Wiley \& Sons, 2008.

28 J. Maier, Physical Chemistry of Ionic Materials: Ions and Electrons in Solids, John Wiley \& Sons, 2004.

29 H. Schmalzried, Solid State Reactions, Vch Pub., 1981.

30 D. Fischer, G. de La Fuente and M. Jansen, Rev. Sci. Instrum., 2012, 83, 043901.

31 H. J. M. Bouwmeester, H. Kruidhof and A. J. Burggraaf, Solid State Ionics, 1994, 72, 185-194.

32 L. Wang, R. Merkle, J. Maier, T. Acartürk and U. Starke, Appl. Phys. Lett., 2009, 94, 071908.

33 J. Claus, M. Leonhardt and J. Maier, J. Phys. Chem. Solids, 2000, 61, 1199-1207. 
34 R. A. De Souza and J. A. Kilner, Solid State Ionics, 1998, 106, 175-187.

35 O. Kubaschewski and B. E. Hopkins, Oxidation of Metals and Alloys, Butterworths, 1967.

36 K. Fueki and J. B. Wagner, J. Electrochem. Soc., 1965, 112, 384-388.

37 D. Caplan, M. Graham and M. Cohen, J. Electrochem. Soc., 1972, 119, 1205-1215.

38 N. Khoi, W. Smeltzer and J. Embury, J. Electrochem. Soc., 1975, 122, 1495-1503.

39 A. Atkinson and R. Taylor, Philos. Mag. A, 1981, 43, 979-998.

40 R. Nakamura, J.-G. Lee, H. Mori and H. Nakajima, Philos. Mag., 2008, 88, 257-264.

41 H. Mehrer, Diffusion in Solids: Fundamentals, Methods, Materials, Diffusion-Controlled Processes, Springer Science \& Business Media, 2007.

42 F. Stott and G. Wood, Corros. Sci., 1977, 17, 647-670.
43 G. Petot-Ervas and C. Petot, J. Phys. Chem. Solids, 1990, 51, 901-906.

44 H. Atkinson, Oxid. Met., 1985, 24, 177-197.

45 A. Atkinson and D. W. Smart, J. Electrochem. Soc., 1988, 135, 2886-2893.

46 A. Atkinson, D. Smart and R. Taylor, Mater. Corros., 1987, 38, 704-709.

47 C. H. Chen, M. R. Notis and D. B. Williams, J. Am. Ceram. Soc., 1983, 66, 566-571.

48 S. Mrowec, J. Nowotny, T. Walec and T. Wojcikiewicz, Bull. Acad. Pol. Sci., Ser. Sci. Chim., 1973, 21, 829-837.

49 W. Chen, N. Peterson and L. Robinson, J. Phys. Chem. Solids, 1973, 34, 705-709.

50 M. Seltzer, J. Electrochem. Soc., 1971, 118, 802-805.

51 A. Atkinson and R. Taylor, J. Phys. Chem. Solids, 1986, 47, 315-323. 